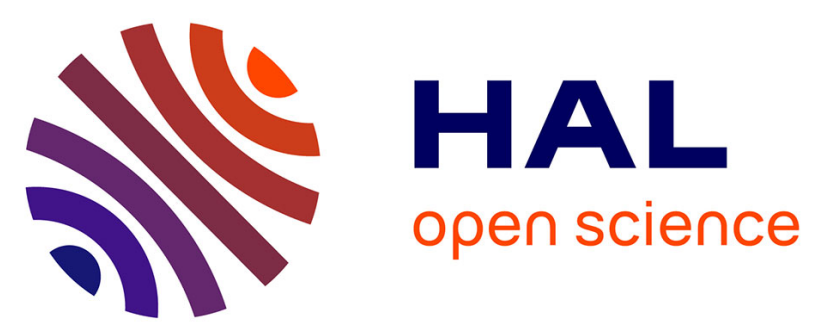

\title{
Heterozygosity and Chain Multivalents during Meiosis Illustrate Ongoing Evolution as a Result of Multiple Holokinetic Chromosome Fusions in the Genus Melinaea (Lepidoptera, Nymphalidae)
}

Melanie Mcclure, Bernard Dutrillaux, Anne-Marie Dutrillaux, Vladimir Lukhtanov, Marianne Elias

\section{To cite this version:}

Melanie Mcclure, Bernard Dutrillaux, Anne-Marie Dutrillaux, Vladimir Lukhtanov, Marianne Elias. Heterozygosity and Chain Multivalents during Meiosis Illustrate Ongoing Evolution as a Result of Multiple Holokinetic Chromosome Fusions in the Genus Melinaea (Lepidoptera, Nymphalidae). Cytogenetic and Genome Research, 2018, 153 (4), pp.213-222. 10.1159/000487107 . hal-02922143

\section{HAL Id: hal-02922143 \\ https://hal.science/hal-02922143}

Submitted on 25 Aug 2020

HAL is a multi-disciplinary open access archive for the deposit and dissemination of scientific research documents, whether they are published or not. The documents may come from teaching and research institutions in France or abroad, or from public or private research centers.
L'archive ouverte pluridisciplinaire HAL, est destinée au dépôt et à la diffusion de documents scientifiques de niveau recherche, publiés ou non, émanant des établissements d'enseignement et de recherche français ou étrangers, des laboratoires publics ou privés. 
Heterozygosity and chain multivalents during meiosis illustrate ongoing evolution as a result of multiple holokinetic chromosome fusions in the genus Melinaea (Lepidoptera, Nymphalidae)

Melanie McClure*1, Bernard Dutrillaux*1, Anne-Marie Dutrillaux ${ }^{1}$, Vladimir Lukhtanov²,3, Marianne Elias ${ }^{1}$

Running title : multiple chromosome fusions in the genus Melinaea

Keywords: Melinaea, butterfly, chromosome fusion, hybrid, meiotic chain

*Equal contribution

1. Institut de Systématique, Évolution, Biodiversité, ISYEB - UMR 7205 - CNRS MNHN UPMC EPHE, Muséum National d'Histoire Naturelle, Sorbonne Universités, 57 rue Cuvier CP50 F-75005, Paris, France

2. Department of Karyosystematics, Zoological Institute of Russian Academy of Sciences, Universitetskaya nab. 1, St. Petersburg, 199034 Russia

3. Department of Entomology, St Petersburg State University, Universitetskaya nab. 7/9, St Petersburg 199034, Russia

Corresponding author: Bernard Dutrillaux, elias@mnhn.fr, +33 140793790 


\begin{abstract}
Mitotic and meiotic chromosomes of two taxa of the genus Melinaea (Lepidoptera: Nymphalidae) and a hybrid cross produced in captivity were obtained, and subsequently analysed, after an improved spreading technique. In one of the taxa, the presence of trivalents and tetravalents at diakinesis/metaphase $\mathrm{I}$ is indicative of heterozygosity for multiple chromosome fusions or fissions, which might explain the highly variable number of chromosomes previously reported for this genus. Two large and complex multivalents were observed in the meiotic cells of hybrid males (32 chromosomes) obtained from a cross between Melinaea 'satevis' tarapotensis (28 chromosomes) and M. satevis cydon (40-43 chromosomes). The contribution of the two different haploid karyotypes to these complex figures during meiosis is discussed, and a taxonomic revision is proposed. We conclude that chromosome evolution is active and ongoing, that the karyotype of the common ancestor consisted of at least 48 chromosomes, and that evolution by chromosome fusion rather than fission is responsible for this pattern. Complex chromosome evolution in this genus may drive reproductive isolation and speciation, and highlights the difficulties inherent to the systematics of this group. We also show that Melinaea chromosomes, classically considered holocentric, are attached to a unique, rather than multiple, spindle fiber.
\end{abstract}

Keywords: atypical holocentric chromosomes, butterfly, chromosomal polymorphism, chromosomal rearrangements, diversification, hybrid, Ithominii

\title{
Introduction
}

The Neotropical butterflies of the genus Melinaea (Nymphalidae: Ithomiini), consisting of 13 species and over 70 subspecies (Lamas 2004), are extensively involved in Müllerian mimicry (Elias and Joron 2015), whereby co-occurring species converge in wing colour patterns that inform predators of their toxicity (Müller 1879). Phylogenetic studies have shown that at least six Melinaea species (M. isocomma, M. marsaeus, M. menophilus, M. mneme, M. mothone and M. satevis), comprised of 38 subspecies, are virtually undistinguishable on the basis of coding mitochondrial and nuclear sequences (Whinnett et al. 2005; Elias et al. 2007; Dasmahapatra et al. 2010; McClure and Elias 2016a), suggesting rapid and extremely recent radiation in this group. Recent findings also question the currently established taxonomy (McClure and Elias 2016a), which was mostly based on wing color pattern elements due to the lack of differentiation in morphological characters such as 
genitalia and legs (Fox 1960), immature stages, and by their similarities in ecology and hostplant use (McClure and Elias 2016b).

This paper focuses on two Melinaea taxa, M. satevis cydon and M. 'satevis' tarapotensis, thought to be conspecifics, which are allopatric and never co-occur. Genetic structure shows the two taxa as being fully separate with reduced gene flow. There appears to be strong pre-mating isolation, and it has been suggested that the taxonomy might need to be revised as they might consist of fully differentiated species rather than subspecies (McClure and Elias 2016a). Unexpectedly, we were recently able to cross $M$. satevis cydon and $M$. 'satevis' tarapotensis and obtain F1 hybrids, providing a means with which to study the behavior of chromosomes during meiosis.

Previous cytogenetic studies performed after fixation of gonads have shown that haploid number of chromosomes, determined by counting the number of bivalent elements in spermatocytes I at metaphase, range from 13 to 30 in the genus Melinaea, and that intraspecific and even intra-subspecific variations are present (Brown et al. 2004). This may indicate that an important chromosomal instability exists and that active chromosomal evolution is on-going.

Unfortunately, chromosomal evolution can be difficult to ascertain, as Lepidoptera possess holocentric chromosomes (Robinson 1971; Wolf 1996; Wolf et al. 1997), and thus lack localized centromeres, which precludes observations of chromosome morphology and karyotyping. Furthermore, their chromosomes are very small: their $\mathrm{C}$-value (haploid genome size) is of approximately $0.30 \mathrm{pg}$, about half that of moths and among the lowest values observed for arthropods (Gregory 2005). Heterochromatin, usually present in centromeric regions, is absent here, or scarce when present, which limits the interest of C-banding. Fortunately, after improving hypotonic shock conditions, we were able to obtain satisfying chromosome spreading of most meiotic stages and reconstruct the causes of chromosome variations in the studied taxa. Our results suggest that the chromosomal evolution of this group of butterflies is one of the most active ever described in insects.

\section{Material and methods}

Rearing conditions. Collection localities consisted of transitional forest habitats near Tarapoto (Rio Shilcayo basin: 6 $27^{\prime} 30^{\prime}$ 'S, $76^{\circ} 21^{\prime} 00^{\prime \prime} \mathrm{W}$ ) and lowland forest on PongoBaranquita road $\left(6^{\circ} 17^{\prime} 53^{\prime}\right.$ S, $\left.76^{\circ} 14^{\prime} 38^{\prime \prime} \mathrm{W}\right)$ in North-Eastern Peru, in 2016. Gravid wildcaught females were placed in 2 × 2 × 2 m outdoor insectaries in Tarapoto, San Martin, where all rearing was carried out (see (McClure and Elias 2016a) for further information). 
Butterflies were provided nourishment in the form of sugar water solution and bee pollen. Potted Juanulloa parasitica were used for oviposition, and larvae collected in the cages were reared individually in transparent plastic containers in the shade behind a nearby building under ambient conditions. Larvae were checked daily for food replacement and cleaning, and J. parasitica leaves were offered ad libitum.

Newly emerged butterflies were kept together with wild caught males in the outdoor insectaries, with sugar water solution and bee pollen for nourishment, and pyrrolizidine alkaloid sources in the form of withered Heliotropium sp. (Boraginaceae) and Eupatorieae (Asteraceae). Cages were checked frequently every day for mating events, and the presence of a spermatophore was ascertained by palping the females' abdomen. Premating isolation is very strong in Melinaea, especially in sympatric species, and as a result interspecific mating pairs rarely occur. When they do, fertile eggs are generally not produced (McClure and Elias 2016a), possibly as a result of gamete incompatibilities. Surprisingly, we were recently able to obtain F1 hybrids between the allopatric M. satevis cydon and M. 'satevis' tarapotensis: two virgin females of $M$. satevis cydon were mated by different wild caught males of M. 'satevis' tarapotensis, and one of these crosses produced F1 progeny.

To further assess fertility of the hybrids in backcrosses, female and male hybrids were kept in separate cages, together with individuals of the parental taxa of the opposite sexes. Cages were checked daily and mating events were recorded. Mated females were provided with potted J. parasitica host-plants, and eggs/larvae were collected regularly.

Specimens used. Testes from seven freshly killed males were used for the modified hypotonic shock technique described below (Table 1). We complemented this sampling with seven additional males whose testes were preserved in a Carnoy's solution in the field several months prior to analysis (Table 1).

Modified hypotonic shock technique. Our usual technique, developed for beetle cytogenetics (Dutrillaux et al. 2011), was modified and adapted in order to account for 1) the relative resistance of the testis membrane to osmotic shock, 2) the small amount of material, and 3 ) the fragility of some meiotic stages. The sole testis, extracted from freshly killed males, was ruptured inside an Eppendorf tube containing $0.5 \mathrm{ml}$ of a slightly hypotonic KCL solution ( 0.88 or $0.84 \mathrm{M}$ in distilled water), with the addition of $5 \mu \mathrm{l}$ of a $4 \mathrm{mg} / \mathrm{l}$ colchicine solution in some instances. After $1 \mathrm{~h}$, one drop of Carnoy I fixative solution was added, the cells were gently suspended, and the tube was centrifuged (about $7 \mathrm{G}$ ). The supernatant was 
replaced with Carnoy I fixative solution for $20 \mathrm{~min}$. After additional centrifugation, the supernatant was replaced with fresh fixative for a few minutes and centrifuged again, after which the pellet (almost invisible at this point) was suspended in the amount of supernatant necessary for two drops of spreading suspension. Each drop was deposited on a wet superfrost slide (Thermo Scientific, Braunschweig, Germany). Giemsa staining and C-banding were performed as described in (Dutrillaux et al. 2010).

Orcein stained specimens. Freshly excised testes from field-caught males were immediately placed in $0.5-\mathrm{ml}$ vials with freshly prepared Carnoy fixative solution. Gonads were stored in fixative for several months at $4^{\circ} \mathrm{C}$ and then stained with $2 \%$ acetic orcein for 30 days at $20^{\circ} \mathrm{C}$. The stained testes were placed in a drop of $40 \%$ lactic acid on a slide, and spermatocysts were dissected from gonad membranes using entomological pins before covering everything with a coverslip. Different degrees of chromosome spreading were observed by gradually increasing pressure on the coverslip.

\section{Results}

M. satevis cydon. Different chromosome arrangements were observed for the three specimens used in the study. In the first specimen, diakineses/metaphases I consisted of 14 bivalents and four trivalents. For the second specimen, diakineses/metaphases I consisted of 15 bivalents, three trivalents and one tetravalent. And finally, for the third specimen, diakineses/metaphases I consisted of 18 bivalents and two trivalents (Fig. 1a, b, c). Table 2 summarizes our interpretation of these results in regards to evolution by chromosome fusions, detailed as follows. Each chromosome of the bivalent corresponds to one ancestral chromosome, and a single type of meiotic segregation is expected. In a trivalent, there are two pairs of ancestral chromosomes that consist of two free chromosomes (chromosomes 1 and 2) and one fused chromosome (chromosome 1-2). Normal segregation will result in either two free chromosomes (chromosomes 1 and 2) or one fused chromosome (chromosome 1-2). In a tetravalent there are three pairs of ancestral chromosomes consisting of two free chromosomes (chromosomes 1 and 3) and two fused chromosomes (chromosome 1-2 and chromosome 2-3). Normal segregation results in one fused chromosome and one unfused chromosome (either chromosome 1-2 and chromosome 3, or chromosome 1 and chromosome 2-3). As such, balanced gametes should contain 18 to 20, 20 to 23, or 20 to 24 chromosomes for the first, second and third specimens respectively. The number of observed mitotic chromosomes is of 40 and 43 for the first and second specimens respectively, which confirms 
the predictions of Table 2. However, no mitotic metaphases were obtained for specimen three. Chromosomal polymorphism is also apparent in the presence or absence of a secondary constriction. Indeed, it is visible during both mitosis and meiosis metaphase on a single chromosome for the first two specimens, and two homologous chromosomes in meiosis of the third specimen (Fig. 1).

Thus, M. s. cydon has highly polymorphic karyotypes and is heterozygous for different fusions, as seen during metaphase I. We deduced that the karyotype of the second specimen was of 48 ancestral chromosomes, and of 44 for that of specimens one and three. This difference can easily be explained by the presence of two additional homozygous fusions present in specimens one and three. The analysis of three additional samples using material fixed with Carnoy solution in the field revealed 18 elements (two samples) and approximately 19 elements (one sample) at metaphase I (Fig. 2a). This observation is in agreement with the previous results. This suggests that the extensive variability observed within these natural populations does not seriously affect meiosis and reproduction, in sharp contrast to the reproductive failure often observed in animals and plants heterozygous for similar levels of chromosomal rearrangements (King 1993).

M. 'satevis' tarapotensis. In both males, mitotic metaphases consist of 28 chromosomes (Fig. 3a), which are on average larger than in M. satevis cydon. At diplotene/diakinesis there are 14 bivalents, which almost always exhibit a chiasma in the median position (Fig. 3b). The karyotypes of the two males tested were similar, and the lack of trivalent/multivalent at diakinesis indicates the lack of heterozygosity for chromosome fusions/fissions in these specimens. Compared to M. s. cydon, the reduced number of chromosomes may indicate that it underwent fewer fissions or more fusions. In four additionally studied field-fixed samples, 14 chromosomal elements were found (most likely bivalents at metaphase I; Fig. 2b, c). This suggests that, unlike in $M$. s. cydon, all chromosomal rearrangements are fixed within $M$. 's.' tarapotensis and no variation is present within this taxon.

Hybrid cross between $M$. satevis cydon $\mathbf{x}$ M. 'satevis' tarapotensis. The two hybrid specimens studied are full sibs and both have mitotic metaphases consisting of 32 chromosomes (Fig. 4). One of the parents, M. 's.' tarapotensis, has a homozygous karytotype of 28 chromosomes and contributed 14 chromosomes. Thus, the M. s. cydon parent contributed 18 chromosomes to this hybrid karyotype. Table 2 indicates that, among the $M$. satevis cydon specimens studied here, only the karyotype of the first specimen is compatible 
with this number of chromosomes. The meiotic figures are very complex, with two aspects observed repeatedly from diplonema to metaphase I. The most frequent configuration observed (configuration 1: 29/45) is characterized by the presence of two large multivalents, one trivalent and seven bivalents (Fig.5). The largest multivalent was interpreted as a nona/decavalent. A secondary constriction is present at one extremity, indicating the distal location of the marked chromosome from M. s. cydon. A bifurcation is present at the other extremity and was initially interpreted as an overlapping bivalent. However, it was almost always observed, which indicates a physical link, i.e. the presence of a chiasma. The second multivalent is interpreted as a heptavalent. In a minority of cells (configuration 2: 16/45), the largest multivalent is replaced with two shorter ones: one heptavalent (1a) and one trivalent (1b) (Fig. 6). The secondary constriction remains at one extremity of the heptavalent, which indicates that the split of the nona/decavalent occurred at the other end. Other figures remain unchanged. No dispersal of bivalents was ever obtained in spermatocytes at pachynema, despite the use of a prolonged hypotonic shock. Many germ cells have a degenerative appearance, but a portion of the spermatocytes appear to progress to metaphase II (Fig. 7a-d). However, at metaphase II the number of chromosomes is highly variable, ranging from 11 to 20 , and suggests that most gametes would have an unbalanced genome. The attachment of chromosomes to the spindle fibers (Fig. 7c, staining with Giemsa after C-banding) shows that the uneven distribution of chromosomes in the two sister spermatocytes II is not the consequence of a spreading artifact, but rather an anomaly during segregation. Unexpectedly, Figure $7 \mathrm{c}$ also shows that each chromosome is attached to a single spindle fiber, and not to multiple fibers as proposed by holokinetic chromosome models (Wolf et al. 1997; Perez et al. 2000; Melters et al. 2012).

\section{Hybrid x parental backcrosses}

Two hybrid females were successfully backcrossed with wild caught males of $M$. satevis cydon. One of the females died without producing any developing eggs. The other female laid over 100 eggs that never developed, although she did also produce four viable offspring (three males and one female) that had wing colour patterns that resemble that of M. s. cydon.

\section{Discussion}

Variation in chromosome numbers. Variation in chromosome numbers in Ithomiini - the tribe that contains the genus Melinaea - obtained by counting the dots that represent compact bivalents in spermatocytes or oocytes at metaphase I or II, have been reported in older studies 
(de Lesse 1970; Brown et al. 1992; Brown et al. 2004). Compared to the almost 250 species reported in these papers, our data are quantitatively anecdotal. However, there has until now been no explanation for the possible mechanisms underlying this inter- and intraspecific variation. With the opportunity to obtain living specimens, and by adapting some basic cytogenetic techniques, we were able to obtain meiotic pictures of reasonable quality and to propose some corresponding interpretations. The first surprising observation is the presence of heterozygosity for chromosomal fusions or fissions in non-hybrid specimens, as demonstrated by the presence of trivalents and tetravalent at diakinesis/metaphase I in $M$. $S$. cydon. Multiple chromosome fusions or fissions in non-hybrid specimens, resulting in trivalents at metaphase I, have also been reported in the genus Leptidea (Lepidoptera, Pieridae (Dinca et al. 2011; Lukhtanov et al. 2011) for which it was subsequently confirmed by using fluorescence in situ hybridization (FISH) technique (Sichova et al. 2015; Sichova et al. 2016).

Evolution by fusion rather than fission. In light of the highly variable number of chromosomes, the lack of data on the ancestral chromosome number makes it difficult to determine whether evolution by fission or fusion is at work. Fortunately, the analysis of meiosis in the hybrids is very informative: the presence of a nona/decavalent and of a heptavalent is highly feasible in the event of evolution by successive fusions. This has been described in mammals, such as in Muridae (Rodentia) and Lemuridae (Primates), in which multiple fusions of acrocentric chromosomes (Robertsonian evolution) have occurred (Capanna et al.1976, Dutrillaux and Rumpler, 1977). For this to be explained by evolution by fissions, the presence of two multivalents in the hybrid would imply the presence of two pairs of giant sized chromosomes in the ancestors, which would have undergone multiple fissions at different loci on the two homologues, a very unlikely scenario. There is therefore strong support for evolution by multiple fusions, although this may differ from Robertsonian evolution; indeed, the lack of distinct centromeres in Lepidoptera, and thus of true acrocentric chromosomes, suggests that another mechanism than centric fusions is at work here.

Interpretation of meiosis in the hybrids. The expected contribution of the M. 'satevis' tarapotensis $(2 \mathrm{n}=28)$ parent to the hybrid karyotype $(2 \mathrm{n}=32)$ is of 14 chromosomes. Thus, that of the M. satevis cydon parent should be of 18 chromosomes. Among the different M. s. cydon studied, only specimen one has a configuration capable of transmitting 18 chromosomes (Table 2). Thus we conclude that the hybrid karyotype of 32 chromosomes received 18 chromosomes, including four fused chromosomes, from a $M$. s. cydon individual 
with the same chromosomal configuration as specimen one of our study, although their relative position remains to be determined. The interpretation for this is given in Figure 8. In spermatocytes with the first configuration (Fig. 5), a chromosome of both parental origin is present in each of the six bivalents. Because M. s. cydon provided four additional chromosomes compared to $M$. 's.' tarapotensis, the extremities of the trivalent and of the two multivalents are expected to consist in a free chromosome from M. s. cydon. There is therefore one remaining $M$. s. cydon chromosome, which is expected to be the one that is subterminally associated with the nonavalent, thus forming an atypical decavalent. This association is likely the result of a single crossing-over at the preceding pachynema. In spermatocytes with the second configuration (Fig. 6), we posit that the arrangement of chromosomes was the same at the pachytene stage, but the occurrence of a double crossingover split the decavalent, thereby forming a trivalent plus a heptavalent at later stages.

Taken together, the complexity of meiosis observed in the hybrids, the presence of strong assortative mating and severely reduced gene flow between $M$. s. cydon and $M$. 's.' tarapotensis (McClure and Elias 2016a) provide strong support for the separation of these two taxa into different species, with the latter renamed as $M$. tarapotensis (revised status). The new taxonomy is applied henceforth.

\section{Chromosome evolution and its implications for diversification in the genus Melinaea.}

Butterflies have the largest range of interspecific chromosome number variation, ranging from $\mathrm{n}=5$ to ca. 224-226, which incidentally is the highest known number in non-polyploid eukaryotic organisms (Lukhtanov 2014; Lukhtanov 2015). Lepidoptera may also harbour strong intraspecific chromosome number variation. The Eurasian taxon Leptidea sinapis (Pieridae), for example, has the highest known level of intraspecific chromosome number variation: within this species, the haploid chromosome number gradually decreases from $\mathrm{n}=$ 53-54 in Spain to $\mathrm{n}=28$ in Kazakhstan (Lukhtanov et al. 2011). These ranges indirectly point to multiple fusions and fissions in the evolution of their karyotype, presenting a drastic change to the ancestral chromosome number in the Lepidoptera, thought to be of 31 chromosomes (Beliajeff 1930; Robinson 1971; Lukhtanov 2000; Brown et al. 2004; Ahola et al. 2014). Brown et al. (2004) studied 10 species and 46 subspecies of the genus Melinaea and reported haploid numbers ranging from 13 to 30, without any clear modal number, although most were between 17 and 24 . This is not very informative as to the evolutionary trend by fusion or fission of the karyotype in this genus. In mammals, fusions seem to occur more frequently than fissions, but this may simply reflect the conceptual difficulty in considering 
chromosome splitting, such as with neo-centromere formation, as was shown in the evolution of Cercopithecinae (Primates) (Dutrillaux et al. 1982). Butterflies are thought to possess holocentric chromosomes, which may facilitate fissions if several potential centromeres are distributed along the chromatids.

Fortunately, the meiotic chromosomes of the hybrid specimens in our study are particularly informative regarding the possible origin of the ancestral chromosomes. The heptavalent is composed of 12 ancestral chromosomes (two chromosomes are unfused and 10 chromosomes are involved in five different fusions; Fig. 8). Two of these fusions were present in the $M$. s. cydon parent and three were present in the M. tarapotensis parent (rev. stat.). At least 16 chromosomes are necessary to explain the formation of the nonavalent chain, in which three fusions were present in the $M$. s. cydon parent and five in the $M$. tarapotensis parent (rev. stat.). However, the association of a bivalent from M. s. cydon with an element from the $M$. tarapotensis nonavalent chain (forming the complex nona/decavalent presented in Fig. 8) indicates that the contributing chromosomes from both parents have undergone the same additional fusion. This increases the number of ancestral chromosome by an additional four. Finally, the four ancestral chromosomes present in the trivalent and the 12 chromosomes present in the six bivalents suggests that their last common ancestor had at least 48 chromosomes, and potentially more if additional fusions were shared by the two taxa.

Thus, we conclude that the evolutionary trend of karyotypes in the genus Melinaea is characterized by multiple chromosome fusions from an ancestral karyotype composed of at least 48 chromosomes. This evolution is obviously still ongoing and likely to generate more or less efficient gametic barriers, depending on the complexity of the resulting meiotic process. In M. s. cydon, for which two to four different fusion events were reconstructed, variations in chromosome numbers appear to be pervasive (both within populations and within individuals) and do not seem to impair the meiosis process. However, a large number of such rearrangements, as those observed in the hybrids between $M$. s. cydon and $M$. tarapotensis (rev. stat.), seems to be highly detrimental to meiosis, thereby causing strong postzygotic isolation via severely reduced hybrid fertility.

The fact that multiple single fusions/fissions resulting in trivalents only weakly affect meiosis and fertility is supported not only by our data of the genus Melinaea, but also by data obtained for the genus Leptidea (Sichova et al. 2015; Sichova et al. 2016) and the subgenus Agrodiaetus (Lepidoptera, Lycaenidae, genus Polyommatus) (Lukhtanov 2015).

High lability in chromosome numbers has been proposed to drive speciation in other butterflies, such as in the Leptidea wood white butterflies (Lukhtanov et al. 2011; Sichova et 
al. 2015) and Agrodiaetus blue butterflies (Lukhtanov et al. 2005; Kandul et al. 2007). Cytogenetic studies of more species of the genus Melinaea are needed to assess whether dynamic evolution of chromosomal rearrangements is pervasive and has contributed to the rapid diversification of this clade.

Atypical holocentric chromosomes. The chromosomes of the genus Melinaea, as those of other butterflies, are morphologically of the holocentric type. Typically, mitotic chromosomes do not display localized centromeres and their chromatids remain tightly associated. Such chromosomes are also thought to be polykinetic, i.e. with kinetochore microtubule attachments scattered along their length (Wolf et al. 1997; Perez et al. 2000; Melters et al. 2012). Consequently, and unlike monocentric chromosomes, they are supposed to be attached to several microtubules during their migration to the poles. As shown in Figure 7, this seems to not be the case: each anaphasic chromosome is attached to one extremity, and not transversally, and seems to be driven by a single, and not multiple, microtubules. This fortuitous observation suggests that Melinaea chromosomes may not fulfill all the criteria for true holocentric chromosomes. Thus, the large variation in chromosome number observed in the genus Melinaea may constitute a perfect argument for the theory that holocentric chromosomes favour rapid karyotypic evolution (Melters et al. 2012), but the facilitation of chromosome fissions would certainly not be the privileged mechanism.

\section{Conclusion}

The large inter- and intraspecific variation in chromosome numbers in butterflies implies a role of chromosomal fusions and fissions in the evolution of karyotypes. However, this evolutionary model has been poorly documented due to the difficulties of chromosome analysis. In the Melinaea species studied here, chromosomal rearrangement polymorphism is present even within populations, with no apparent deleterious effect on meiosis. However, accumulation of such multiple rearrangements in diverging lineages results in the formation of chain multivalents in hybrids, thereby impairing meiosis and leading to the production of unbalanced gametes in such hybrids, and ultimately, driving speciation. Our results raise important questions on the role that chromosomal rearrangements may play in the rapid radiation of the genus Melinaea, and warrants further investigation.

\section{Acknowledgements}


We thank the Peruvian authorities (002-2015-SERFOR-DGGSPFFS), the PEHCBM-Area de Conservacion Regional Cordillera Escalera (023-2016/GRSM/PEHCBM/DMA/ACR-CE), and the Museum Nacional de Historia Natural in Lima and its director Gerardo Lamas for providing research and export permits. We also thank field assistants Ronald Mori-Pezo, Josh Richard and Mario Tuanama, and Keith Willmott regarding taxonomic revisions. This work was funded by a grant from the French National Research Agency to ME (grant SPECREP, ANR-14-CE02-0011). MM is funded by a postdoctoral grant on the SPECREP project. VL was supported by the grant N 14-14-00541 from the Russian Science Foundation to the Zoological Institute of the Russian Academy of Sciences.

\section{References}

Ahola V, et al. (2014) The Glanville fritillary genome retains an ancient karyotype and reveals selective chromosomal fusions in Lepidoptera. Nature Communications 5.

Beccaloni GW (1997) Ecology, behaviour and natural history of ithomiine butterflies (Lepidoptera: Nymphalidae) and their mimics in Ecuador. Trop. Lep. 8: 103-124.

Beliajeff NK (1930) Die Chromosomekomplexe and ihre Beziehung zur Phylogenie bei den Lepidopteren. Zeitschrift für induktive Abstammungs- und Vererbungslehre 54: 369399.

Britton-Davidian J, et al. (2000) Environmental genetics - Rapid chromosomal evolution in island mice. Nature 403: 158-158.

Brown KS, Emmel TC, Eliazar PJ, Suomalainen E (1992) Evolutionary patterns in chromosome numbers in neotropical Lepidoptera. 1. Chromosomes of the Heliconiini (family Nymphalidae, subfamily Nymphalinae). Hereditas 117: 109-125.

Brown KS, von Schoultz B, Suomalainen E (2004) Chromosome evolution in Neotropical Danainae and Ithomiinae (Lepidoptera). Hereditas 141: 216-236.

Capanna E, Gropp A, Winking H, Noack G, Civitelli MV (1976) Robertsonian metacentrics in mouse. Chromosoma 58: 341-353.

Chazot N, et al. (2016) Into the Andes: multiple independent colonizations drive montane diversity in the Neotropical clearwing butterflies Godyridina. Mol. Ecol. 25: 57655784.

Dasmahapatra KK, Lamas G, Simpson F, Mallet J (2010) The anatomy of a 'suture zone' in Amazonian butterflies: a coalescent-based test for vicariant geographic divergence and speciation. Mol. Ecol. 19: 4283-4301. 
De-Silva DL, Elias M, Willmott K, Mallet J, Day JJ (2016) Diversification of clearwing butterflies with the rise of the Andes. J. Biogeogr. 43: 44-58.

de-Silva DL, et al. (2017) Northern Andean origin and diversification of the largest ithomiine butterfly genus. Scientific Reports 7: 45966.

de Lesse H (1960) Spéciation et variation chromosomique chez les Lépidoptères Rhopalocères. Annales des Sciences Naturelles Zoologie et Biologie Animale, 12e série 2: 1-223.

de Lesse H (1970) Les nombres chromosomiques chez les Lépidoptères Rhopalocères en Amérique centrale et Colombie. Annales De La Societe Entomologique De France 3: 347-358.

Dinca V, Lukhtanov VA, Talavera G, Vila R (2011) Unexpected layers of cryptic diversity in wood white Leptidea butterflies. Nature Communications 2.

Dutrillaux AM, Pluot-Sigwalt D, Dutrillaux B (2010) (Ovo-)viviparity in the darkling beetle, Alegoria castelnaui (Tenebrioninae: Ulomini), from Guadeloupe. European Journal of Entomology 107: 481-485.

Dutrillaux B, Couturier J, Muleris M, Lombard M, Chauvier G (1982) Chromosomal phylogeny of 42 species or subspecies of cercopithecoids (primates Catarrhini). Annales De Genetique 25: 96-109.

Dutrillaux B, Rumpler Y (1977) Chromosomal evolution in Malagasy lemurs II. Meiosis in intra- and interspecific hybrids in the genus Lemur Cytogenet Cell Genet 18: 197-211.

Elias M, et al. (2007) Limited performance of DNA barcoding in a diverse community of tropical butterflies. Proc. R. Soc. B 274: 2881-2889.

Elias M, Joron M (2015) Mimicry in Heliconius and Ithomiini butterflies: the profound consequences of an adaptation. . Bio Web of Conferences 4: 00008.

Elias M, et al. (2009) Out of the Andes: patterns of diversification in clearwing butterflies. Mol. Ecol. 18: 1716-1729.

Fox RM (1960) A monograph of the Ithomiidae (Lepidoptera), Part II. The tribe Melinaeini Clark. Transactions of the American Entomological Society 86 86: 109-171.

Gregory TR (2005). Genome size evolution in animals. The evolution of genome. Gregory TR. San Diego, Elsevier 3-87.

Jiggins CD, Mallarino R, Willmott KR, Bermingham E (2006) The phylogenetic pattern of speciation and wing pattern change in neotropical Ithomia butterflies (Lepidoptera : Nymphalidae). Evolution 60: 1454-1466. 
Joron M (2005) Polymorphic mimicry, microhabitat use, and sex-specific behaviour. J. Evol. Biol. 18: 547-556.

Kandul NR, Lukhtanov VA, Pierce NE (2007) Karyotypic diversity and speciation in Agrodiaetus butterflies. Evolution 61: 546-559.

King M (1993). Species evolution: the role of chromosomal change. Cambridge Cambridge University Press.

Lamas G (2004). Ithomiinae in J. B. Heppner, ed. Atlas of Neotropical Lepidoptera. Checklist: Part 4A. Hesperioidea - Papilionoidea. . Gainsville, Association for Tropical Lepidoptera/Scientific Publishers.

Lukhtanov VA (2000) Sex chromatin and sex chromosome systems in nonditrysian Lepidoptera (Insecta). Journal of Zoological Systematics and Evolutionary Research 38: 73-79.

Lukhtanov VA (2014) Chromosome number evolution in skippers (Lepidoptera, Hesperiidae). Comparative Cytogenetics 8: 275-291.

Lukhtanov VA (2015) The blue butterfly Polyommatus (Plebicula) atlanticus (Lepidoptera, Lycaenidae) holds the record of the highest number of chromosomes in the nonpolyploid eukaryotic organisms. Comparative Cytogenetics 9: 683-690.

Lukhtanov VA, Dinca V, Talavera G, Vila R (2011) Unprecedented within-species chromosome number cline in the Wood White butterfly Leptidea sinapis and its significance for karyotype evolution and speciation. BMC Evol. Biol. 11.

Lukhtanov VA, Kandul NP, Plotkin JB, Dantchenko AV, Haig D, Pierce NE (2005) Reinforcement of pre-zygotic isolation and karyotype evolution in Agrodiaetus butterflies. Nature 436: 385-389.

McClure M, Elias M (2016a) Ecology, life history, and genetic differentiation in the Neotropical Melinaea (Nymphalidae: ithomiini) butterflies from north-eastern Peru. . Zoological Journal of the Linnean Society Early view. .

McClure M, Elias M (2016b) Unravelling the role of host plant expansion in the diversification of a Neotropical butterfly genus. BMC Evol. Biol. 16: 128.

Melters DP, Paliulis LV, Korf IF, Chan SWL (2012) Holocentric chromosomes: convergent evolution, meiotic adaptations, and genomic analysis. Chromosome Research 20: 579593.

Müller F (1879) Ituna and Thyridia: a remarkable case of mimicry in butterflies. Transactions of the Entomological Society of London 1879: xx-xxix. 
Perez R, Rufas JS, Suja JA, Page J, Panzera F (2000) Meiosis in holocentric chromosomes: orientation and segregation of an autosome and sex chromosomes in Triatoma infestans (Heteroptera). Chromosome Research 8: 17-25.

Robinson R (1971). Lepidoptera Genetics, Pergamon Press.

Schulz S, et al. (2004) Semiochemicals derived from pyrrolizidine alkaloids in male ithomiine butterflies (Lepidoptera : Nymphalidae : Ithomiinae). Biochemical Systematics And Ecology 32: 699-713.

Sichova J, Ohno M, Dinca V, Watanabe M, Sahara K, Marec F (2016) Fissions, fusions, and translocations shaped the karyotype and multiple sex chromosome constitution of the northeast-Asian wood white butterfly, Leptidea amurensis. Biol. J. Linnean Soc. 118: 457-471.

Sichova J, et al. (2015) Dynamic karyotype evolution and unique sex determination systems in Leptidea wood white butterflies. BMC Evol. Biol. 15.

Trigo JR (2011) Effects of pyrrolizidine alkaloids through different trophic levels. Phytochemistry Reviews 10: 83-98.

Whinnett A, et al. (2005) Strikingly variable divergence times inferred across an Amazonian butterfly 'suture zone'. Proc. R. Soc. B 272: 2525-2533.

Wolf KW (1996) The structure of condensed chromosomes in mitosis and meiosis of insects. International Journal of Insect Morphology \& Embryology 25: 37-62.

Wolf KW, Novak K, Marec F (1997) Kinetic organization of metaphase I bivalents in spermatogenesis of Lepidoptera and Trichoptera species with small chromosome numbers. Heredity 79: 135-143. 
Table 1. The number of male specimens of two Melinaea taxa and one hybrid cross used for this study, either after hypotonic shock technique, or by Orcein staining after preservation of the testis in a Carnoy's solution

\begin{tabular}{lcc}
\hline Taxa & Hypotonic shock & Orcein staining \\
\hline Melinaea satevis cydon & 3 & 3 \\
Melinaea 'satevis' tarapotensis & 2 & 4 \\
hybrid of M. 's.' tarapotensis X M. s. cydon & 2 & 0 \\
\hline
\end{tabular}

Table 2. Chromosome data for three specimens of Melinaea satevis cydon. The interpretation of the metaphase I bivalents, trivalents and tetravalents permits the reconstruction of the number of ancestral chromosomes and to predict the chromosome composition of the gametes.

\begin{tabular}{lccc}
\hline Specimen & $\mathbf{1}$ & $\mathbf{2}$ & $\mathbf{3}$ \\
\hline Number of bivalents & 14 & 15 & 18 \\
Number of chromosomes & 28 & 30 & 36 \\
Minimum number of ancestral chromosomes & 28 & 30 & 36 \\
$\quad$ Number of inheritable chromosomes & 14 & 15 & 18 \\
\hline Number of trivalents & 4 & 3 & 2 \\
Number of chromosomes & 12 & 9 & 6 \\
Minimum number of ancestral chromosomes & 16 & 12 & 8 \\
$\quad$ Number of inheritable chromosomes & $4-8$ & $3-6$ & $2-4$ \\
\hline Number of tetravalents & 0 & 1 & 0 \\
Number of chromosomes & 0 & 4 & 0 \\
Minimum number of ancestral chromosomes & 0 & 6 & 0 \\
$\quad$ Number of inheritable chromosomes & 0 & 2 & 0 \\
\hline Total number of chromosomes & 40 & 43 & 42 \\
\hline Total number of ancestral chromosomes & 44 & 48 & 44 \\
\hline Expected number of chromosomes in a balanced gamete & $18-22$ & $20-23$ & $20-24$ \\
\hline
\end{tabular}


Figure legends

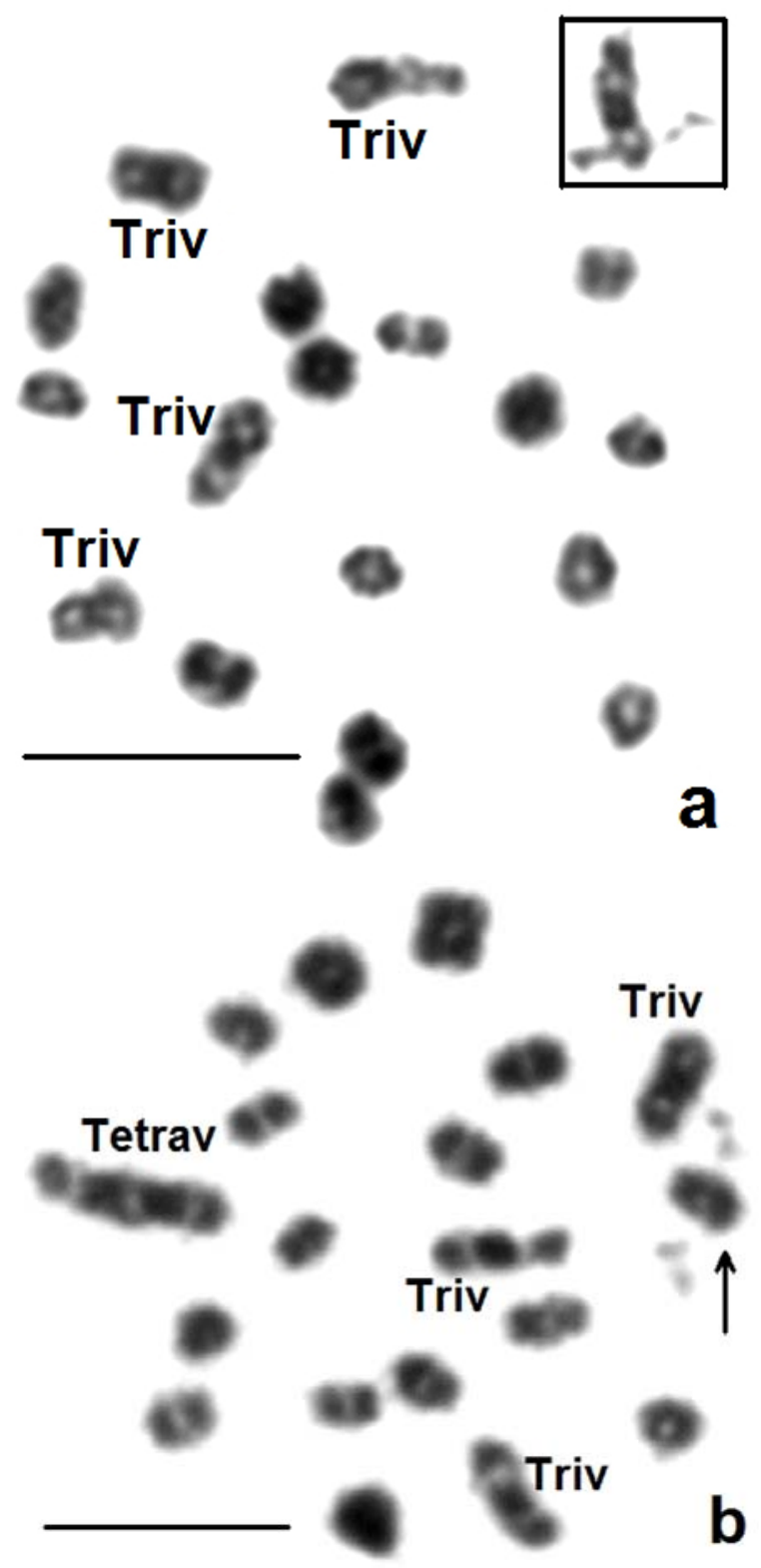




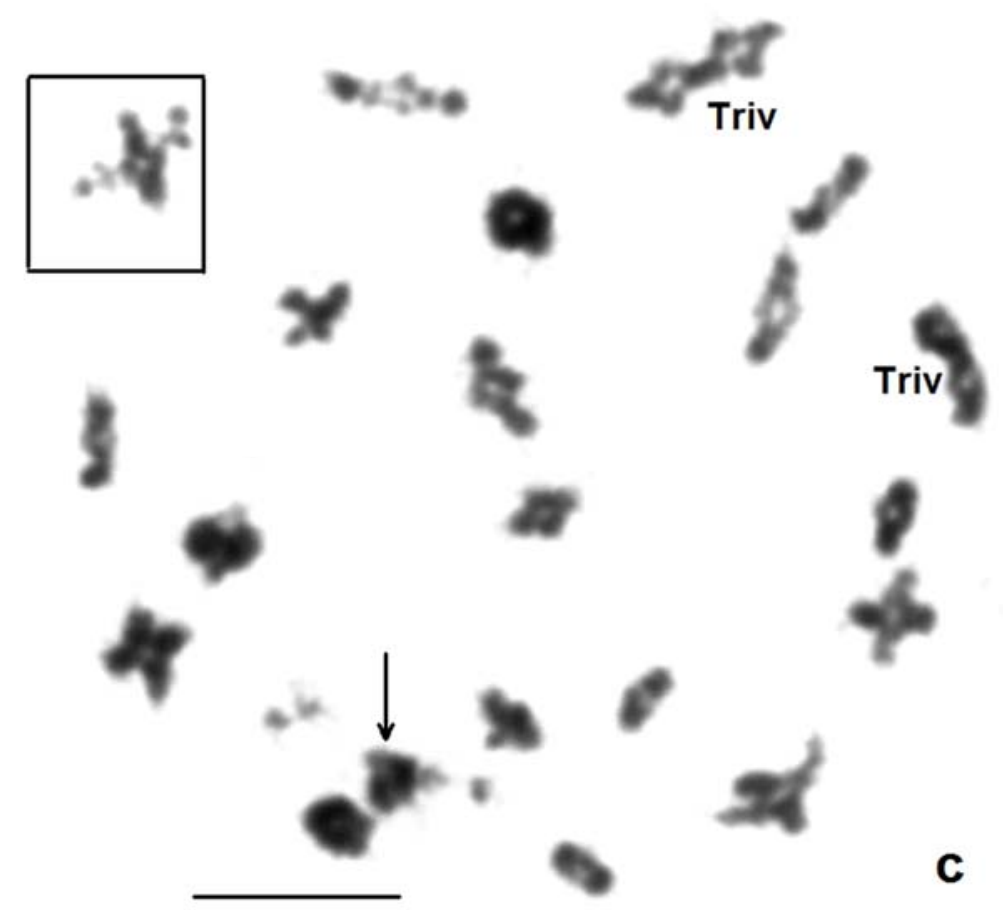

Figure 1 Melinaea satevis cydon. Giemsa stained diakineses/metaphases I of three specimens. (a) Four trivalents are present in the first specimen. Two homologs with satellites (marked chromosomes) contribute to a trivalent (top and inset from another cell). (b) One tetravalent and three trivalents are present in the second specimen. The two marked chromosomes form a bivalent (arrow). (c) Two trivalents are present in the third specimen. The two marked chromosomes form a bivalent (arrow and inset from another cell).

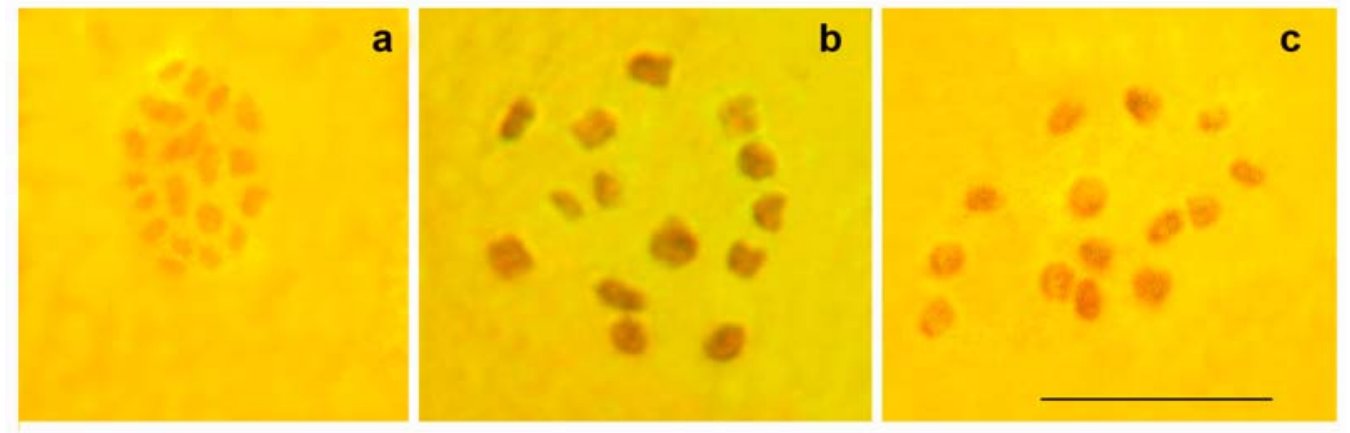

Figure 2 Orcein stained metaphase I plates of (a) Melinaea satevis cydon with 19 chromosomal elements; (b) Melinaea 'satevis' tarapotensis with 14 chromosomal elements; (c) Melinaea 'satevis' tarapotensis with 14 chromosomal elements. Bar $=10 \mu \mathrm{m}$ 

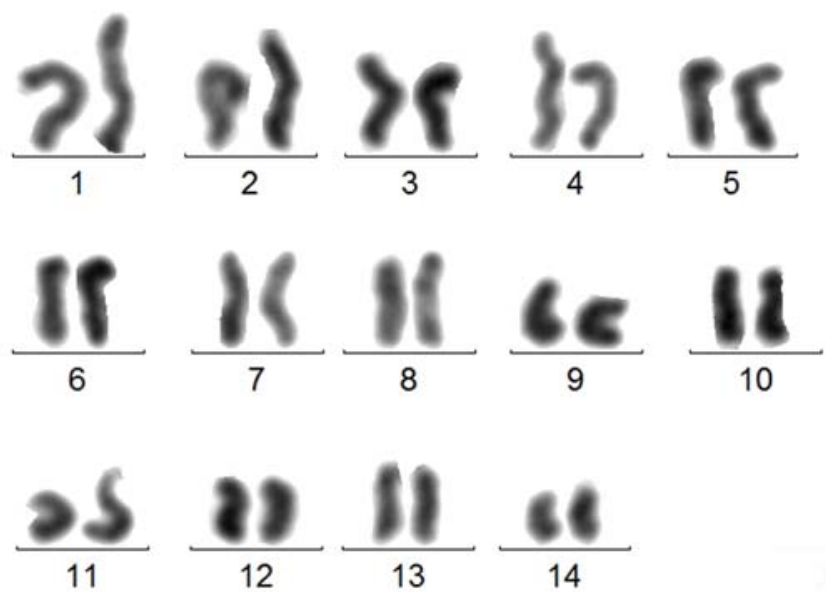

b

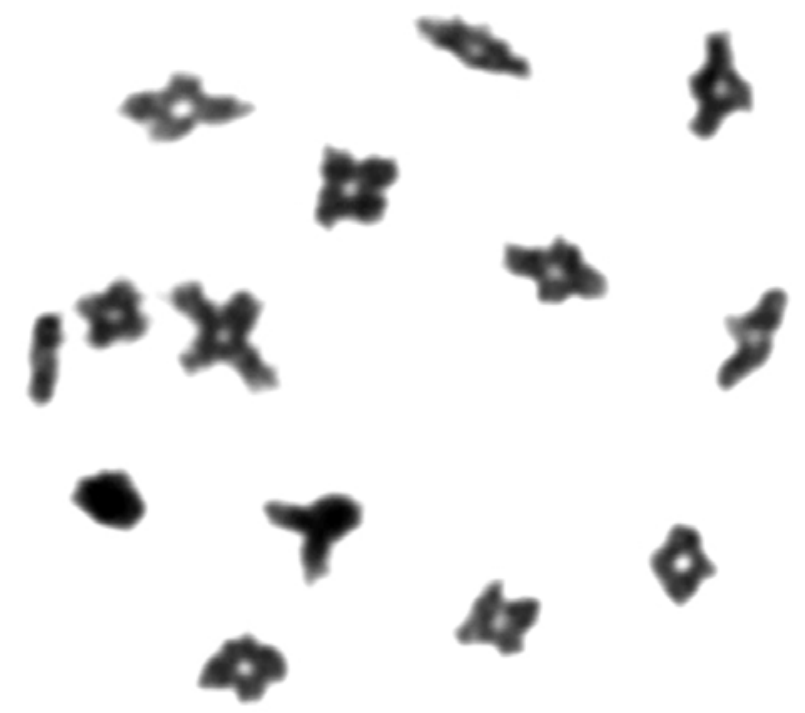

Figure 3 Melinaea 'satevis' tarapotensis (a) Giemsa stained karyotype. (b) Early diakinesis with14 bivalents: almost all bivalents have a chiasma in the median position. 


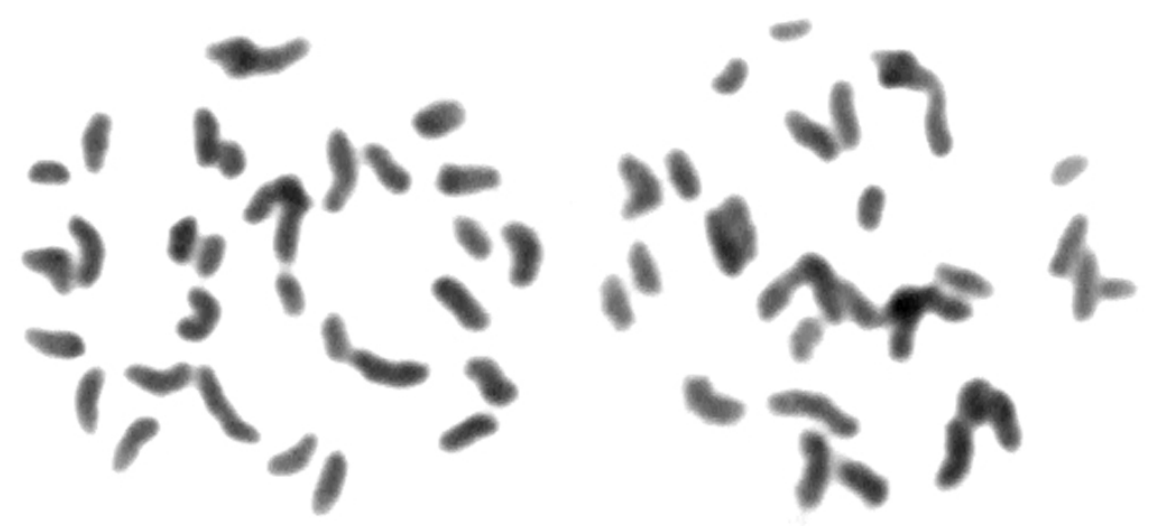

Figure 4 Hybrid cross of $M$. satevis cydon $x M$. 'satevis' tarapotensis. Two mitotic metaphases with 32 chromosomes.

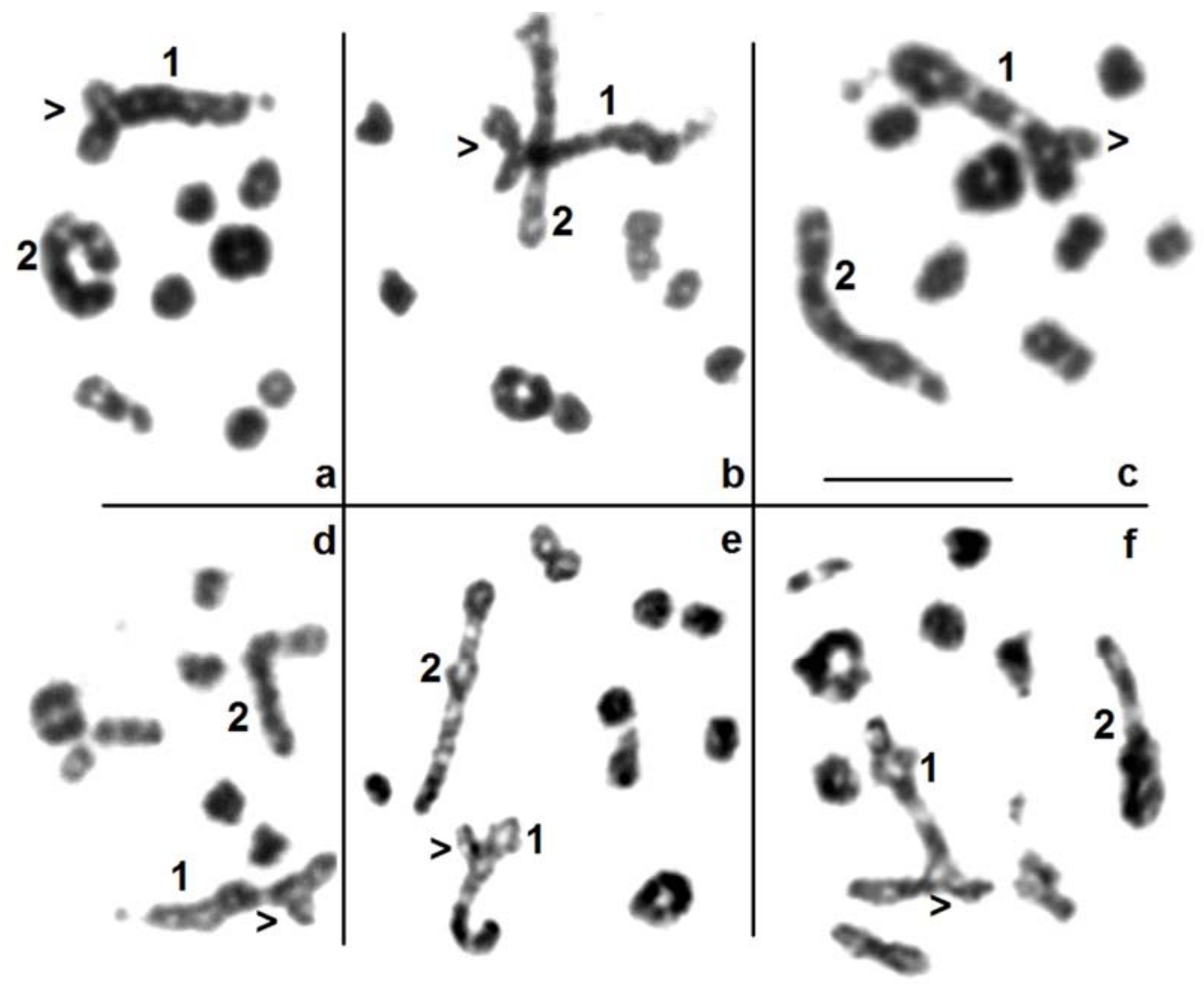

Figure 5 a-f Diakinesis/metaphase I of the $M$. satevis cydon $x$ M. 'satevis' tarapotensis hybrid cross, displaying two large multivalents (one nona/decavalent and one heptavalent). The largest one has a sub-terminal bifurcation (arrow head) or is associated with a monovalent. A trivalent, a large ring bivalent and five smaller bivalents are also present. 


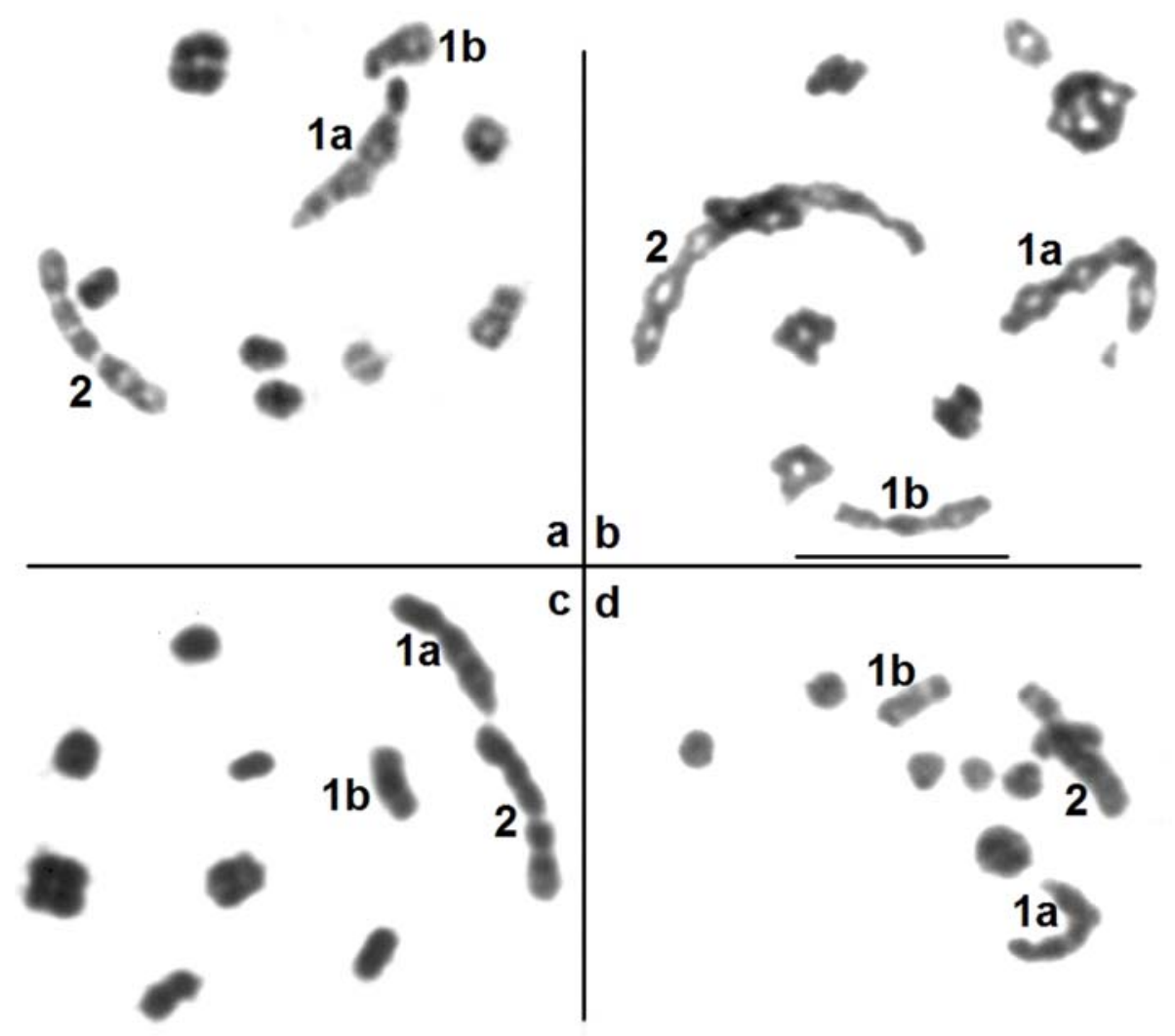

Figure 6 a-d Other diakineses/metaphase I of the M. satevis cydon $x$ M. 'satevis' tarapotensis hybrid cross in which the heptavalent (2) remains unchanged and the nona/decavalent is replaced with two shorter multivalents: one heptavalent (1a) and one trivalent (1b). 


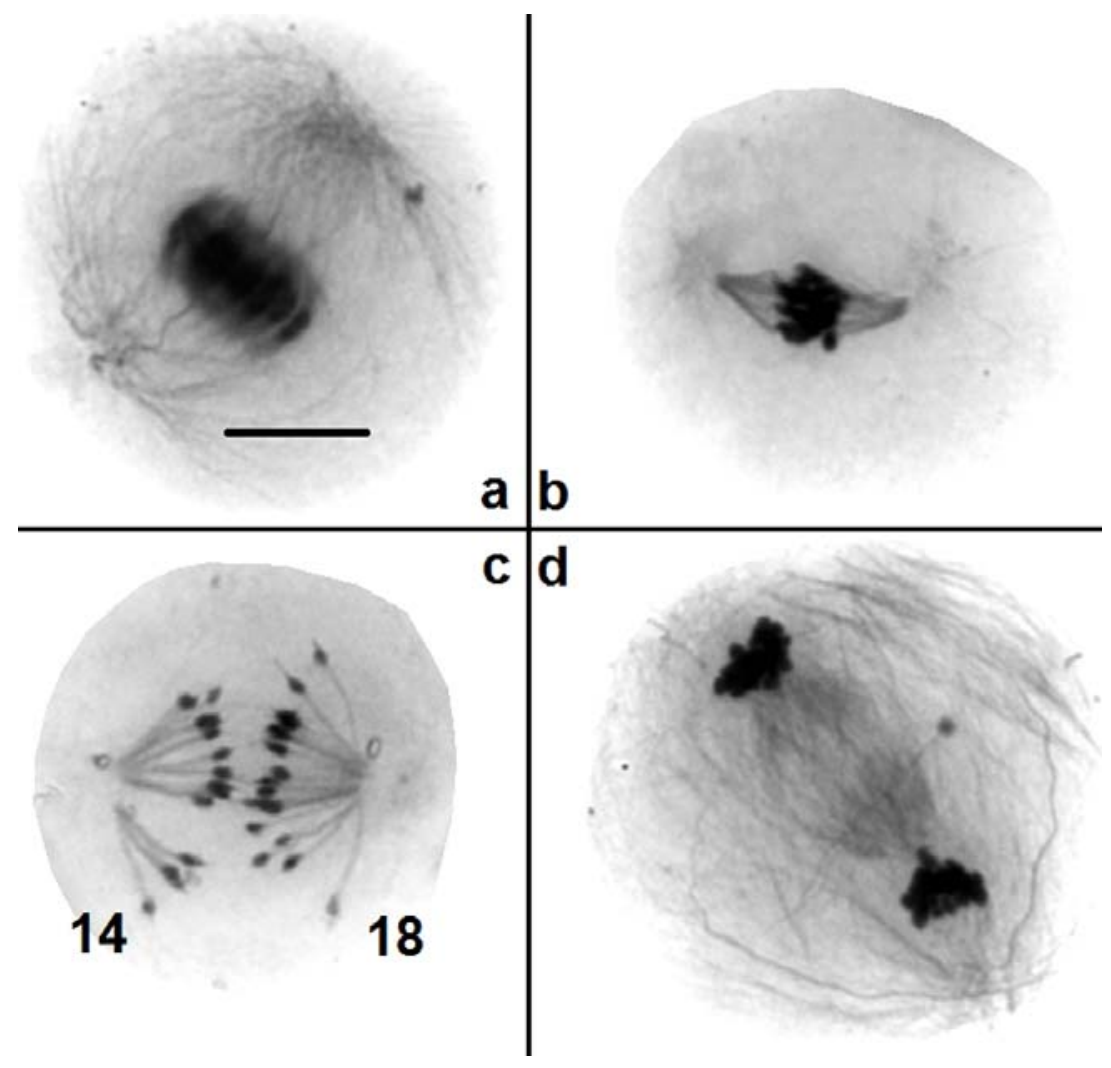

Figure 7 Metaphase I (a), anaphase I (b,c) and telophase I (d), with Giemsa staining of the microtubules after C-banding, suggesting a normal progression from spermatocyte I to spermatocyte II in some cells of the M. satevis cydon $x$ M. 'satevis' tarapotensis hybrids. However, the segregation of the chromosomes is uneven, with two sets of 14 and 18 chromosomes (c). Note that at anaphase, chromosomes are attached to a single fiber (c). 

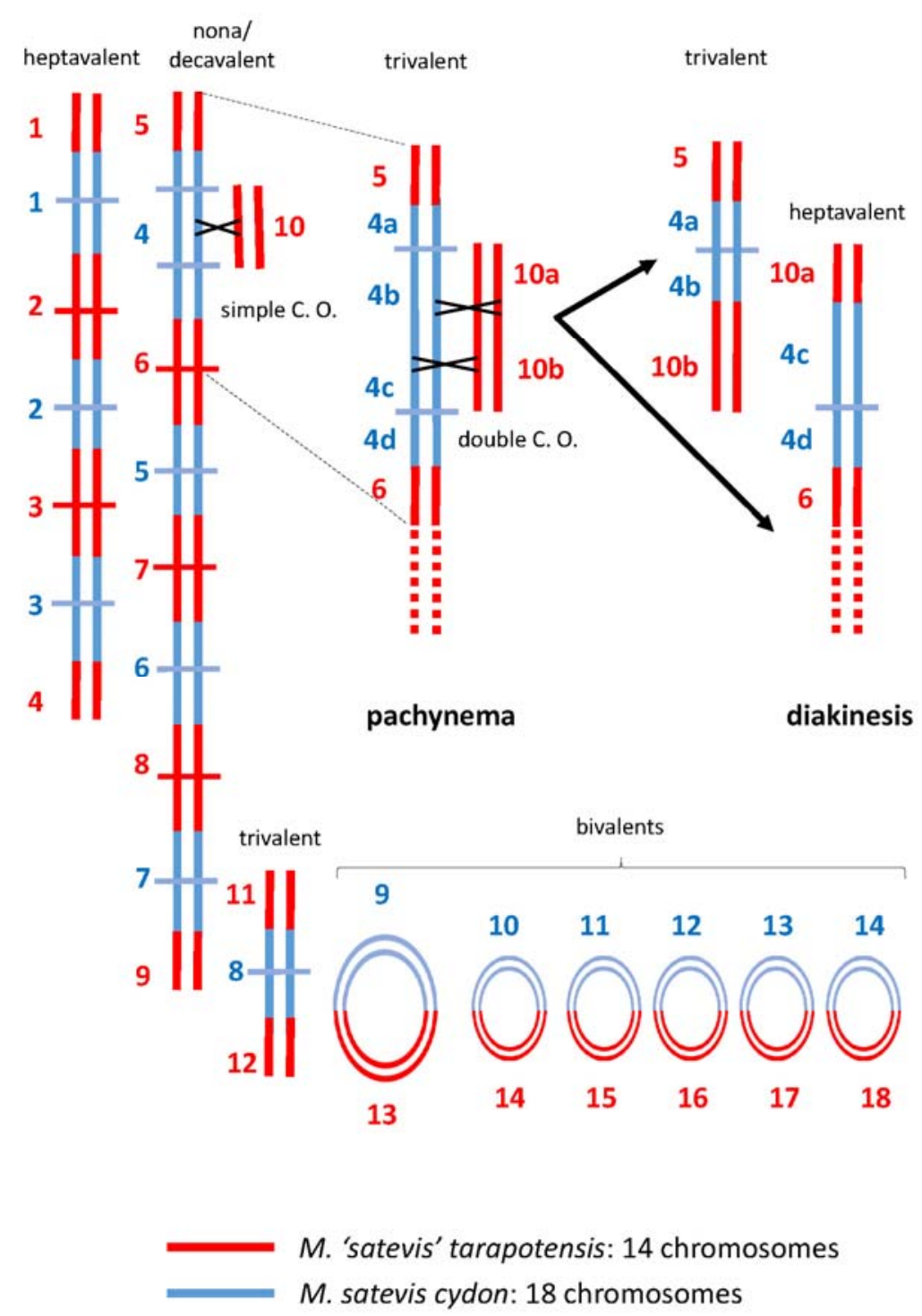

Figure 8 Schematic representation of the chromosome arrangement at diakinesis of the $\boldsymbol{M}$. satevis cydon x M. 'satevis' tarapotensis hybrids as observed in Figure 5. From left to right: one heptavalent, one nona/decavalent, five small bivalents, one large ring bivalent, and one trivalent. Chromosomes are presented as a single line and are in an end-to-end association; as such, chiasma are not shown. The segment $a-b$, corresponding to the region of superposition/bifurcation of the nona/decavalent in Figure 5, has been enlarged and presented with its two chromatids so as to show that a double crossing-over event during pachynema can split it and form one heptavalent and one trivalent, as observed in Figure 5. The bottom of the heptavalent is not presented. The arrows indicate the points of fusion. 